\title{
The Debate about the Human Papilloma Virus Vaccine: The Impact of an Evidence-based Communicative Method on Increasing Free Choice
}

\author{
Maria del Mar Ramis
}

\begin{abstract}
Democratic access to scientific evidence contributes to the freedom of individuals to make informed decisions regarding scientific findings that affect their lives. In the case of the human papilloma virus (HPV), which causes cervical cancer, a debate exists regarding preventing HPV infection that is not supported by evidence-based interventions. For instance, there are positions both in favor of and against an HPV vaccine that are not evidence-based, thus preventing women from deciding freely whether to be vaccinated. Based on a communicative approach, this article describes the use of communicative focus groups and communicative daily life stories in which the researcher shares up-to-date information on HPV prevention, particularly through vaccination and screening, with high-schoolgirls in an urban context in Spain. Through the focus groups and daily life stories, the young women evaluated the impact of evidence-based dialogues, which could increase their opportunities to make free choices regarding the HPV vaccine and other medicines.
\end{abstract}

Keywords: Human Papilloma Virus Vaccine, Evidence-based communicative method, communicative focus groups, communicative daily life stories 
On 17 November 2015, UNESCO adopted Resolution 38C/70, which declared 28 September of every year International Day for Universal Access to Information. The day was first celebrated in 2016 and represented the success of numerous efforts by diverse actors. Universal access to information and knowledge is a goal that requires access to the Internet as well as education and training that facilitate the appropriate selection of relevant knowledge. Access to knowledge and freedom of information are key features of developed societies, and the laws of many countries recognize the right of citizens to request certain governmental records (Walby \& Larsen, 2012). Regarding the use of such data in qualitative inquiries, Walby and Larsen (2012) argue that this opportunity has yet not been capitalized on by qualitative researchers probably because of an association with news-value-oriented journalism and the consideration that such research might involve a non-interactive method (Walby \& Larsen, 2012). In our research, we observe how young women interact with straightforward data, including governmental recommendations, and contribute new insights into HPV prevention and the significance of citizen access to knowledge.

Today more than ever, citizens are the main actors in their lives and able to provoke changes and transformations as well as to make decisions that were previously impossible. These circumstances result from what Beck (1992) termed the risk society, whereby risk is understood as "a systematic way of dealing with hazards and insecurities induced and introduced by modernization itself (Beck 1992:21)" that also affects the confidence citizens have in science and scientific progress (Price \& Peterson, 2016). Although these risks include matters over which we have no control -such as natural hazards- the decisions affected by risks are often highly personal, such as employment or health issues. The information society is also confronting an era in which inequalities are determined not only by access to resources but also to information (or the lack of it), including its quantity and quality (Bucy, 2000).

It is important to consider that the potential benefits of access to information do not affect everyone in the same way, and inequalities in access and skills remain present (Brodie et al., 2000). Paradoxically, the more information that is shared on the Internet, the more disadvantaged individuals with access difficulties or low skills become because they do not have the opportunity to become informed. This problem is particularly relevant in the case of 
health information because today individuals are increasingly required to make informed decisions that were traditionally made for them by health-care providers.

The scientific debate on the prevention of cervical cancer includes groups that are in favor of the Human Papilloma Virus (HPV) vaccine and groups that oppose it, and the scientific literature provides evidence on both sides (Schiffman, Castle, Jeronimo, Rodriguez, \& Wacholder, 2007). However, the public debate regarding the vaccine often does not focus on the scientific evidence but on other factors. The group that opposes the vaccine focuses on two major arguments: the economic interests of the laboratories behind the vaccine's commercialization and the vaccine's alleged terrible side effects. In contrast, the group that favors the vaccine states that it has no secondary effects. Neither argument is fully supported by scientific evidence.

In this paper, I explain in detail dialogues held with young women regarding the scientific evidence on HPV, the HPV vaccine and the virus's relationship with cervical cancer. My purpose was to share such evidence with young students in vocational training in a public high school of a city in the Barcelona metropolitan area and to evaluate the extent to which a communicative method (i.e., an evidence-based debate) can increase participant opportunities for free choice. The approach provided the girls with updated findings regarding HPV and cervical cancer that were relevant to their health and also important because many of the findings are available from open resources to which the participants have direct access. In what follows, I first introduce some of the evidence that was discussed. Subsequently, I explain the communicative focus group and the daily life stories as well as present the results.

\section{The Human Papilloma Virus: a current debate}

Spain's rate of incidence of cervical cancer is 9.1, and the country's mortality rate for the same disease is 2.7 points. In comparison, the EU median rates are approximately 11.3 and 3.7, respectively (EUCAN, 2012). Worldwide, cervical cancer is among the most important cancer types according to 2012 data from the World Health Organization (Ferlay, 2015) although the data per country are highly diverse because they depend on screening coverage 
and the homogeneity of the population. For instance, the data for Europe identify remarkable contrasts between old and new EU member states, which can probably be explained by differences in the implementation of preventative strategies (Arbyn, Raifu, Weiderpass, Bray, \& Anttila, 2009). The cause of most cases of cervical cancer is persistent infection with one of the genotypes of HPV that are carcinogenical though most women with HPV do not develop cancer (World Health Organisation Media Center, 2016). Infection is common in young women in their first decade of sexual activity. Not all infections develop into cancer because this development requires persistent infection and a pre-cancer that occurs in less than $10 \%$ of new infections (Schiffman, Castle, Jeronimo, Rodriguez, \& Wacholder, 2007). Currently, a vaccine is available against four HPV genotypes. The vaccine can in fact prevent certain HPV virus infections (Bosch et al., 1995) but not all. However, to demonstrate that on this basis cervical cancer can be prevented will require years of additional research (Schiffman et al., 2007).

To date, it has been proven that vaccination reduces HPV, and although HPV vaccines can prevent certain HPV infections and cervical pre-cancers, vaccination's impact on women with a current infection or following treatment for a related lesion is not known (Hildesheim, 2016). Therefore, it cannot be stated that the HPV vaccine prevents cervical cancer because insufficient evidence exists to support such a statement (Schiffman et al., 2007).

Additionally, this type of cancer can be substantially avoided through regular screening with a specific test - the Papanicolau test- that identifies the presence or absence of abnormal cells and through treatment of the identified lesions. These tests have been highly important in the treatment of cervical cancer.

According to the most recent evidence, the risk of incurring cervical cancer in EU countries, such as Spain, is low because the illness can be prevented with regular cytological screening (The American Cancer Society medical and editorial content team, 2016). Therefore, in countries in which the presence of cervical cancer as a cause of death is residual, such as Spain, it is challenging to justify universal vaccination against HPV with a vaccine whose safety has not been assured (because of the impossibility of knowing its mid- and long-term 
effects).

The dilemma involves more that an ideological question. Certain individuals understand that if the risk of a vaccine has not been demonstrated it can be administered. Others believe that a vaccine or other preventative measure intended for administration to a healthy population must first demonstrate its efficacy (in this case, that it actually contributes to preventing cervical cancer) and its safety, particularly if the population that will receive the measure has a low prevalence of the health problem to be addressed. What I attempt to show in the following is that access to relevant knowledge through the development of communicative techniques enables citizens -young women in this case- to make free decisions informed by the most relevant scientific evidence gained through an open dialogue. This process not only significantly impacted the lives of the participants but also generated meaningful insights into the usefulness and meaning of the conducted research.

\section{How the Communicative Focus Group and Communicative Daily Life Stories Conducted with Young Women Created the Conditions for Social Impact}

The communicative method builds on Mead's interactionism (Mead, 1934), in which the researcher and the researched contribute knowledge through an intersubjective dialogue. The former contributes the scientific evidence on the topic being addressed, and the latter contributes knowledge from his or her lifeworld (Habermas, 1984) while building on common sense to explain a person's actions (Schutz, 1967). This communicative research promotes a human construction by which meanings are created through dialogue that people hold to give meaning to things and processes around us (Tellado, 2017: 18). The power of dialogic interaction to revisit and re-create meaning has been shown in many contexts and with different agents - from young children (García-Carrión \& Villardón-Gallego, 2016) to adult learners in popular quarters (Aubert, Villarejo, Cabré, \& Santos, 2016) or the Roma people (Garcia-Espinel, Aso, Redondo-Sama \& Flecha, 2017) -to have a transformative effect. As a consequence, through this dialogic interaction, the communicative techniques enable us to generate a social impact by sharing knowledge that is directly relevant to the 
lives of the participants while at the same time creating the conditions the participants require to evaluate this social impact. Among various reasons, this outcome is possible because these techniques are applied in steps that enable a contrast between the information that the researcher presents with that contributed by the other participants that helps them evaluate the extent to which a positive consequence has materialized. In this manner, the technique accomplishes the desired social impact. To achieve this goal, it is important that each participant's role in the process is made explicit and transparent: the researcher provides research evidence and the researched provide knowledge from their lifeworlds. Such strict identification of roles has been identified as contributing to the validity of the knowledge production (Call-Cummings, 2016). In what follows, I attempt to elucidate this process.

To develop this study, I established a communicative focus group (CFG) with five students between 18 and 26 years of age and elicited a communicative daily life story (CDL) from each. The young women were students in vocational education at a high school in one of the largest cities in Catalonia on the Barcelona outskirts. They were studying to obtain the Certificate on Promotion of Gender Equality. The context in which they live is defined by the character of the city, which is divided into seven districts that to a large extent are home to a population of workers. Ana, Júlia, Patricia, Shayma (of Muslim origin; wears an Islamic scarf), and Mireia come from working-class backgrounds that are traditionally not academic. However, most of the young women had determined to pursue a university degree on completing high school.

The girls had been contacted by one of their teachers, who explained the purpose of the study and outlined the techniques. Information and consent forms were provided to obtain the young women's agreement to participate first in the CFG and several days later in the CDLS. The goal of the CFG was twofold. On the one hand, I aimed to introduce the topic of HPV and its relation to cervical cancer by providing scientific evidence to the participants and facilitating a dialogue based on that evidence. On the other hand, I wanted to have a debate with these young women on the relevance of the scientific evidence for them as young women and on the importance of all citizens having access to scientific evidence that is relevant for their lives. This second aspect was to be analyzed in greater depth during the 
CDLS. Based on the guidelines of the communicative method -according to which one should seek to apply the technique in the participants' natural context-, for the CFG, an appointment was made with all five participants to meet at their school. Their teacher was requested to introduce the researcher to the participants. Following this first contact, one week later, I arranged individual appointments with each participant to conduct the CDLS. These meetings were held in the same setting used for the CFG. The 5 CDLS were elicited on two days, 2 the first day and the remaining 3 on the following day according to the wishes of the participants. The primary purpose of the second meeting was to create a space for dialogue in which a more personal narrative could be elaborated that included information the young women wanted to share regarding their personal experience and their reflections on the impact of the CFG. Importantly, participants mentioned that the atmosphere and confidence that was created with the CFG facilitated the sharing of information during the CDLS, and subsequently highly relevant decisions and impacts were identified, as will be shown in the following.

The CFG started with a brief introduction of the technique followed by a presentation of the topic and relevant data on the HPV. Information was provided by the researcher on the incidence and prevalence of HPV, ways of infection as well as identification and treatment. The goal was to introduce the young women to information and evidence regarding HPV and the HPV vaccine that could be used to start a joint debate with all participants. Next, details concerning the incidence and mortality of cervical cancer and its relationship with HPV were shared. All of the participants were increasingly interested, and a climate developed that facilitated posing complex questions that might not easily arise in another context and that were highly relevant to correctly addressing an infection. As a consequence, the discussion facilitated sharing personal experiences and knowledge -or their lack - and posing questions or expressing doubts regarding the issue. The dialogue was highly open and enabled me to introduce more detailed information by providing answers based on the scientific evidence.

At this point, basic information on the existing vaccines and the virus they address as well as evidence regarding the possible consequences of the HPV vaccine were introduced. Details were included regarding what can and cannot be stated according to the available scientific 
evidence. This part of the dialogue included references to the conclusions of articles from the most relevant scientific sources and introducing the group to the Vaccine Adverse Event Reporting System database (https://vaers.hhs.gov/index). Together, we examined the results of a database search to understand how it is used and the type of information that it provides. I also helped the group learn the difference between emerging indicators and confirmed evidence and to understand the importance of having access to such information. The participants were highly interested and acknowledged the significance of having access to such data as a means of facilitating the freedom to make their own decisions.

\section{Results: evidence of improved health care and increasing the social impact}

Having access to this information gives you more freedom; by having it you can decide what to do; otherwise you are doomed; you have to decide from a very low vantage point, while having this information gives you lots of freedom. (Shayma, CFG)

Two main findings can be drawn from the development of this study. On the one hand, I collected qualitative data on the scientific evidence that confirm that the communicative method can clearly contribute to ensuring the social impact of research. On the other hand, the communicative techniques that were used drew attention to particular elements of the method that facilitate this impact. In what follows, I elaborate these findings through the voices of the study participants. First, I provide evidence of the particular impact on their lives that was derived from their participation in the study. Second, I indicate several dimensions of the communicative method that the participants highlighted as relevant in this process.

One of the most powerful and direct effects was that 3 out of 5 of the participants determined to request an appointment with a doctor for HPV screening. The three participants interpreted this decision as a consequence of their participation in the study, which obviously had a positive effect on their attitude toward personal health:

In fact, from the moment we had the meeting, I asked for an appointment with the 
gynecologist because I want to have a check-up...because I never even thought if I could have HPV or not; so, from that moment, I decided that I will have it checked. (Mireia, CDLS).

Shayma also explained that she determined to request HPV screening as a consequence of a conversation with a girlfriend, which, importantly, shows the power of intersubjective reflection (Mead, 1934) deriving from the communicative method:

I was telling a friend what we talked about, about HPV, and she told me that there were girls who never go to the gynecologist, for instance. And I told her (giggles): "I never go to the gynecologist" and she said: "Really, how come?" I don't like it, I don't feel comfortable, and if I ever did it is because I have pain or something, but to go on a yearly visit, no, no. And then she told me that it's very important that you get screened, and then I was looking a bit, and now I will go at least once a year. Because I had the information, I reacted to what she said, because I knew that it was essential. If she would have said any other nonsense...no. (Shayma, CDLS)

The power of the shared information and the way in which it was shared is evident in the empowerment of these young women to make decisions concerning their health. The increased capacity to make decisions, particularly better-informed decisions, was identified by all the young women as a positive outcome of their participation in the dialogues:

I really liked it a lot. Yes, for me, it was a very beautiful opportunity to be able to talk; we were all here, with you and the data. I don't know, I liked it. And regarding my capacity of deciding, it has had a positive influence (Patricia, CDLS).

The young women clearly mentioned the impact that these dialogues had for them with respect to making better decisions, being more cautious and being more aware of the consequences of their behavior:

Indirectly, I think this [having had this discussion in this way] will make me be more cautious and more aware that this can happen to me and to any person. It will make me decide in a more responsible way (Mireia, CDLS) 
In addition to the impact on their lives, the young women acknowledged the impact that the experience will have beyond themselves. As they expressed it, the knowledge that they acquired is not to be kept to themselves but rather will be extended to other circles and endusers, increasing the social impact:

And since I have done this, I can talk about it more also within my own environment, and I have the opportunity to start to question this topic of HPV, which we had never done before. And for the future, there will be more continuity; I will take it more into account, and I will try to take care of this, and... I will also try to have my friends to have a check-up too (Mireia, $C D L S)$.

Beyond what was learned regarding HPV, the sheer reflection on the importance of having access to information and knowing what to do with it was experienced as empowering:

The idea is not about the vaccine yes or not, it's about knowing to be able to be free so that your decision is based on evidence, and that you are free, because many times you can decide influenced by other points of view or people; you are deciding, but you are not free (...). (Shayma, CDLS)

The same participant continued by highlighting the extent to which her participation in the study and the dialogues and the empowerment she obtained increased her awareness of her ability to decide by herself independently of other individuals:

In the future, I will not just settle for what someone tells me (...).It [having participated in the CFG] gave me more awareness and more capacity to tell: I am a person able to decide for myself, not because you are a doctor you need to decide for me; (...) it's about empowering people to be able to decide (Shayma, CDLS).

From this first approach to the topic with these young women, I could see that the type of information provided - scientific evidence- and the way this information was provided- the climate in which the dialogues occurred- seemed to play an important role in the decisions that were made and how the participant would act in the future concerning her health and well-being. Therefore, following the requisites for the correct development of the CFG and the CDLS was essential for the creation of an atmosphere that approached the ideal 
conditions of dialogue and for the construction of a collective interpretation of what was being analyzed. In the pursuit of a greater social impact of science - which is a relevant challenge for the social sciences and humanities research (Flecha, Soler-Gallart \& Sordé, 2015; Soler-Gallart, 2017), these are two relevant factors to be considered, and as such their impact was assessed by the participants, who pinpointed several elements that made the techniques particularly interesting for them:

It is a reduced group, being only five giving eachother our opinion (...); and the fact that you did explain things, but at the same time you posed questions, it was like...all together, although it is you who know about the topic, you gave importance to all of us, and all of our opinions were valid; this I think is very important. If you [the expert] are the only one giving information, it becomes boring; there is a moment where you just lose the thread of what is being told. But the other way [the communicative focus group], as you are also interacting, you are attentive and you can discuss, you can talk (...) (Shayma, CDLS).

Importantly, another of the elements that was mentioned in the participants' analysis was the disruption of the interpretative hierarchy (Gómez, Racionero, \& Sordé, 2010), which this method promotes and which the participants explained as a key factor for the successful development of the CFG:

I think this is good because...for me...it was clear that you knew more about the topic, but in this way you, it was a little bit like to break with the hierarchy; you left us the space for..., if you would have told us everything at once, then we'd feel like: wow, we know nothing about this, she knows everything and then what do we say. So, you gave us a clue, a piece of information, and then we were pulling from there (Shayma, CDLS)

The participants highly valued two main factors: that relevant scientific information was being shared with them and that this practice counteracted the privilege that certain, more favored citizens have with respect to accessing knowledge:

From the very first time, the way you treated us has been very comfortable and very correct. I think that you provide a space to be able to talk openly, with honesty and in an undisturbed 
way. The fact that we are provided scientific data is awesome, is great. What perhaps I value the most is that a group of people can talk freely with someone that is investigating and who brings research closer to more people, to everyone. (Patricia, CDLS)

Having access to the data, to an explanation and information sources in a natural context promoted awareness of relevant knowledge that was accessible for them and to which they can turn in the future to clarify issues that concern their health:

I think it is very good to have the sources of information you provided us with, and the opportunity to talk about this with the classmates and with you, and be able to create this space for debate. You also gave us information that I didn't know and that it's often not discussed; so, it is very positive (Patricia, FG)

These aspects, which were highlighted in the dialogue during the CFG, were also highlighted by the participants during the personal conversations of the CDLS, as we can note in the following assessment by Ana when she was explaining what she thought of the experience of participating in a $\mathrm{CFG}$ :

Very positive, if you are talking about a certain topic, what else do you want than getting information about what you are talking about to be able to have more a critical opinion when you need to discuss something (...). It is very positive that we are provided sources in which to find reliable information (Ana, CDLS).

\section{Conclusions}

Creating a dialogue situation in which I - as the researcher- shared scientific evidence with the young women who participated in the research enabled the women to have access to information that has had an impact on their lives and helped them make freer decisions by themselves.

In addition, my approach has enabled me to determine the conditions that best facilitate the social impact of scientific knowledge and how the communicative method can play a critical 
role in encouraging this impact. One such condition is access to evidence. The second is the way this evidence is shared, discussed and assimilated. Here, interactions are critical, and the communicative method, because of its nature, reveals how it successfully facilitates interactions. Interactions with peers and relevant others played a critical role in influencing what the participants did in response to the information they received, i.e., whether they took action and why. These aspects must be further investigated, and communicative techniques have much to contribute to such research by providing spaces in which interaction is promoted and multiplied.

Our work as social researchers not only advances science but it also is deeply concerned with the social impact of science, that is, that scientific evidence reaches citizens in a way that enables them to make free decisions that can improve their welfare. The communicative method enables the researcher to proceed further in the evaluation of how scientific evidence affects the improvement of individual lives. Among the techniques used in the communicative method, CFG and the CDLS played a key role, particularly when used in combination. Here, the initial contact between the researcher and the participants in a CFG facilitated the creation of an ideal climate and the sharing of scientific evidence. Subsequently, complementing CFG with CDLS provides evidence of how CFG affects participants through collecting their insights regarding it. Through the communicative techniques that I developed with young women from a suburban town near Barcelona, I witnessed how opening a debate and sharing scientific evidence enabled individuals to improve their lives, subsequently increasing the social impact of science. It was not only deeply inspiring as a woman to share relevant scientific information with young women and thus to promote their informed free choice. It was also particularly rewarding as a scientist to confirm that it is in the hands of people that scientific knowledge regains its core meaning: to improve society's living conditions. A final quotation from Shayma is illuminating in this regard:

To have knowledge, sound and expert knowledge, is very important for everything; you don't need to know everything, but having access to the information ....it is actually a privilege limited to some people, and I think the world of knowledge is too institutionalized, and sometimes it seems that opening a debate would mean for some to lose a privilege, right? (...) 
It is a "class question", I think. Access means freedom, and to be able to speak about this is a privilege because normally we don't. (Shayma, $F G$ ) 


\section{References}

Aubert, A., Villarejo, B., Cabré, J., Santos, T. (2016). Teachers College Record, 118(4), 1-32.

Arbyn, M., Raifu, A. O., Weiderpass, E., Bray, F., \&Anttila, A. (2009). Trends of cervical cancer mortality in the member states of the European Union. European Journal of Cancer, 45(15), 2640-2648.

Beck, U. (1992). Risk Society, Towards a New Modernity. London: Sage Publications. p. 260.

Bosch, F. X., Manos, M. M., Muñoz, N., Sherman, M., Jansen, A. M., Peto, J., \& Shan, K. V. (1995). Prevalence of human papillomavirus in cervical cancer: a worldwide perspective. Journal of the National cancer institute, 87(11), 796-802.

Bucy, E. P. (2000). Social access to the Internet. Harvard International Journal of Press/ Politics, 5(1), 50-61.

Brodie, M., Flournoy, R. E., Altman, D. E., Blendon, R. J., Benson, J. M., \& Rosenbaum, M. D. (2000). Health information, the Internet, and the digital divide. Health affairs, 19(6), 255-265

Call-Cummings, M. (2016). Establishing Communicative Validity Discovering Theory Through Practice. Qualitative Inquiry, 1077800416657101.

Cuzick, J., Clavel, C., Petry, K. U., Meijer, C. J., Hoyer, H., Ratnam, S., \& Iftner, T. (2006). Overview of the European and North American studies on HPV testing in primary cervical cancer screening. International Journal of Cancer, 119(5), 1095-1101.

EUCAN (2012). Estimated incidence, mortality and prevalence, 2012, Retrieved from World Health Organisation's International Agency for Research on Cancer Cervical cancer: http://eco.iarc.fr/eucan/CancerOne.aspx?Cancer=25\&Gender=2

Ferlay, J., Soerjomataram, I., Dikshit, R., Eser, S., Mathers, C., Rebelo, M., \& Bray, F. (2015). Cancer incidence and mortality worldwide: sources, methods and major patterns in GLOBOCAN 2012. International journal of cancer, 136(5), E359-E386.

Flecha, R., Soler-Gallart, M., \&Sordé, T. (2015). Social impact: Europe must fund social sciences. Nature, 528(7581), 193-193.

García-Carrión, R., \&Villardón-Gallego, L. (2016). Dialogue and interaction in early childhood education: A systematic review. REMIE Multidisciplinary Journal of Educational Research, 6(1), 51.

Garcia-Espinel, T., Aso, L., Redondo-Sama, G., \&Flecha, A. (2017). Roma Never Die Alone. 
Qualitative Health Research, 1049732317729138.

Gómez, A., Racionero, S., \&Sordé, T. (2010). Ten years of critical communicative methodology. International Review of Qualitative Research, 3(1), 17-43.

Habermas, J. (1984). The theory of communicative action, volume I. Boston: Beacon.

Hildesheim, A., Gonzalez, P., Kreimer, A. R., Wacholder, S., Schussler, J., Rodriguez, A. C., \& Lowy, D. R. (2016). Impact of human papillomavirus (HPV) 16 and 18 vaccination on prevalent infections and rates of cervical lesions after excisional treatment. American journal of obstetrics and gynecology, 215(2), 212-e1.

Mead, G. H. (1934). Mind, self and society (Vol. 111). University of Chicago Press.: Chicago.

Price, A. M., \& Peterson, L. P. (2016). Scientific progress, risk, and development: Explaining attitudes toward science cross-nationally. International Sociology, 31(1), 57-80.

Tellado, I. (2017). Bridges between individuals and communities: dialogic participation fueling meaningful social engagement. Research on Ageing and Social Policy,5(1), 8-31. doi: 10.4471/rasp.2017.2389

The American Cancer Society medical and editorial content team (2016)The American Cancer Society Guidelines for the Prevention and Early Detection of Cervical Cancer, Retrieved from: https://www.cancer.org/cancer/cervical-cancer/prevention-and-earlydetection/cervical-cancer-screening-guidelines.html

Schiffman, M., Castle, P. E., Jeronimo, J., Rodriguez, A. C., \&Wacholder, S. (2007). Human papillomavirus and cervical cancer. The Lancet, 370(9590), 890-907.

Schutz, A. (1967). The phenomenology of the social world. Northwestern University Press.

Soler-Gallart, M. (2017). Achieving social impact. Sociology in the Public Sphere, Springer Briefs in Sociology.

UNESCO (2015). PROCLAMATION OF 28 SEPTEMBER AS THE “INTERNATIONAL DAY FOR THE UNIVERSAL ACCESS TO INFORMATION" Retrieved from: http://unesdoc.unesco.org/images/0023/002352/235297e.pdf

Walby, K., \& Larsen, M. (2012). Access to information and freedom of information requests: Neglected means of data production in the social sciences. Qualitative Inquiry, 18(1), $31-42$.

World Health Organisation Media Center (2016). Human Papiloma Virus and cervical cancer factsheet Retrieved from: http://www.who.int/mediacentre/factsheets/fs380/en 
